Review Article

\title{
A Short Review on the Valorisation of Sugarcane Bagasse Ash in the Manufacture of Stabilized/Sintered Earth Blocks and Tiles
}

\author{
Jijo James ${ }^{1}$ and P. Kasinatha Pandian ${ }^{2}$ \\ ${ }^{1}$ Tagore Engineering College, Rathinamangalam, Melakkottaiyur (PO), Chennai 600127, India \\ ${ }^{2}$ Karpaga Vinayaga College of Engineering and Technology, Padalam, Kanchipuram District, Tamil Nadu 603 308, India \\ Correspondence should be addressed to Jijo James; jijothegreat@gmail.com
}

Received 28 June 2016; Revised 6 September 2016; Accepted 12 December 2016; Published 3 February 2017

Academic Editor: Antonio Riveiro

Copyright (C) 2017 Jijo James and P. Kasinatha Pandian. This is an open access article distributed under the Creative Commons Attribution License, which permits unrestricted use, distribution, and reproduction in any medium, provided the original work is properly cited.

\begin{abstract}
Valorisation of solid wastes in the manufacture of soil based building materials is one of the several technically feasible and costeffective solutions for waste management. Sugarcane bagasse ash is one such solid waste generated in huge quantities in India, a leading sugar producer. This paper aims at reviewing the valorisation of sugarcane bagasse ash in the manufacture of stabilized as well as sintered earth blocks. Sugarcane bagasse ash is a silica rich material that can play the role of an effective pozzolan leading to enhanced pozzolanic reactions resulting in better performing building materials. The reviewed literature reveals that it has been utilized in the manufacture of blocks as well as tiles in the form of an auxiliary additive as well as a primary stabilizer. However, its utilization in stabilized blocks has been more common compared to sintered blocks due to higher energy consumption in the latter. To summarize, sugarcane bagasse ash not only has improved performance in most of the cases but also has reduced the cost of the material, leading to the conclusion that its valorisation in manufacture of blocks and tiles is a genuine and highly productive solution for waste management as well as cost economy.
\end{abstract}

\section{Introduction}

Compressed stabilized soil or earth blocks are unfired blocks that are made of soil, stabilized with a binder, with or without the addition of fibres and compressed to form the block. The conventional fired bricks have been the mainstay of construction activities over the past several decades. However, in recent times, due to shortage of raw materials, rising material, and labour costs, the construction industry has started to look for other cost-effective alternatives. Traditional soil based constructions like soil blocks, rammed earth, and stabilized earth have again started to gain popularity due to their costeffectiveness being the primary reason. The energy spent in firing of traditional bricks is close to ten times higher than typical cement stabilized soil blocks [1]. Traditional compressed soil blocks are cost-effective, fire-resistant, and easy to use, consume less energy for manufacture, and perform well in various climatic conditions with easy availability of raw materials. However, they do not perform well in the durability front and still do not have widespread acceptance [2]. With the increasing popularity of the stabilized blocks, a lot of researchers have started concentrating on the beneficial use of solid wastes as raw materials in the manufacture of soil blocks. Solid wastes have become a sought-after resource for manufacture of construction materials due to their easy availability in sufficient quantities at cheap cost while also providing an avenue for their reuse and management. Soil engineering, especially soil stabilization, has become an avenue for management of solid wastes with lots of researchers involved in identifying the potential applications of various solid wastes $[3,4]$. A lot of researchers have particularly started concentrating on the use of solid wastes in manufacture of bricks and blocks [5-10]. The utilization of solid wastes has been done either as a standalone stabilizer for the soil block or in the form of secondary additives to primary stabilizers like cement or lime. Sugarcane bagasse ash is one such solid waste that is produced from the sugar industry. It is produced due to the burning of bagasse remains after extraction of cane juice. Bagasse is used as fuel in cogeneration boilers for steam generation used in manufacture of sugar as well as 
generation of electricity. It is usually burnt around $500^{\circ} \mathrm{C}$ in controlled conditions for achieving maximum calorific value [11]. Bagasse ash produced during the burning of sugarcane bagasse ash comes from two sources. One is the bottom ash that settles at the bottom of the boilers collected directly, whereas the second is the fly ash which is obtained from the washing of the chimney gases $[12,13]$. The ashes have both organic (charcoal and bagasse debris) and inorganic (silica) constituents. However, fly ashes have more charcoal when compared to bottom ashes [13]. In some plants, the makeup of the collection system results in a mixture of both bottom and fly ashes [12]. The organic fractions can be used for manufacture of adsorbents [14] and fuel briquettes [13], whereas the inorganic fractions can be used for manufacture of ceramics [15-17] and bricks [18]. Bagasse ash has gained economic importance in recent times due to discovery of several other potential areas of applications including ash filters [19], concrete $[12,20]$, and soil engineering applications like soil stabilization [21-23] and stabilized soil blocks. However, the authors have only concentrated on the application of bagasse ash in the manufacture of stabilized/sintered soil blocks and tiles. Though sintering consumes more energy compared to stabilized soil block manufacture, it has been included to give an alternate perspective of bagasse ash utilization. The quantity and quality of the ash produced during burning depend on the material burnt and the technology used [13]. Effective and complete combustion of the material will lead to reduced quantum of impurities, unburnt and partially burnt organic matter. The source material will influence the type and quantum of minerals present in bagasse of the cane resulting in variations in composition of the ash after combustion. The particle size of a material can play an important role in its cementitious nature [24]. Pretreatment of the ash like sieving through fine mesh sieves or milling it to finer size in a ball mill will result in smaller particle sizes and, hence, improved reactivity. Thus, the effectiveness of the ash as a pozzolan in stabilized blocks will depend on the presence of impurities in the ash, the quantum of impurities if present, the nature of silica in the ash, whether it is crystalline or amorphous, and whether the ash has been modified/treated to improve its reactivity. Thus, this review aims at giving an overview on the characterization and valorisation of bagasse ash in the manufacture of stabilized/sintered soil blocks/tiles with a focus on the aforementioned factors.

\section{Sugarcane Bagasse Ash}

Sugarcane bagasse ash is a solid waste generated from the sugar manufacturing industry. India produced 342.56 million tonnes of sugarcane in the year 2011-12, making it one of the world's biggest cane producers [25]. The sugar manufacturing process generates sugarcane trash, bagasse, bagasse fly ash, press mud, and spent wash $[14,26,27]$. The wastes that are of economic importance are bagasse, molasses, and filter press mud [27]. Bagasse is the fibrous residue remaining after the extraction of the cane juice from sugarcane. Sugarcane bagasse consists of approximately $50 \%$ of cellulose, $25 \%$ of hemicellulose, and $25 \%$ of lignin [28]. In a lot of sugarcane industries, the bagasse generated is usually used as fuel
TABLE 1: Leaching of metals from bagasse ash $(\mathrm{mg} / \mathrm{L})$ [18].

\begin{tabular}{lcc}
\hline Metal & Bagasse ash & Brazilian limits \\
\hline $\mathrm{Ag}$ & $<0.013$ & 5.0 \\
$\mathrm{As}$ & 0.0086 & 1.0 \\
$\mathrm{Ba}$ & $<0.41$ & 70.0 \\
$\mathrm{Cd}$ & $<0.012$ & 0.5 \\
$\mathrm{Cr}$ (total) & $<0.01$ & 5.0 \\
$\mathrm{Hg}$ & 0.0002 & 0.1 \\
$\mathrm{~Pb}$ & $<0.03$ & 1.0 \\
\hline
\end{tabular}

while also reducing its volume for disposal. This residual ash generated from burning or incineration is called bagasse ash inclusive of both bottom and fly ashes. In most modern plants, the bottom ash gets mixed with fly ash in the water channel that comes from the gas washer [13]. This waste is typically disposed of into pits and is also applied on land as soil amendment in some areas [14].

The ecotoxicity of bagasse ash was evaluated by Faria et al. [18] and it was recommended to consider sugarcane bagasse ash as a nonhazardous waste material. However, being nonhazardous does not necessarily mean it has no impact on the environment. Teixeira and Lora [29] concluded in their work that emission of nitrous oxide from bagasse boilers assists the emission standards demanded in the European community. Moreover, they noticed an increase in nitrous oxide emissions with reduction in boiler load and fuel consumption, thereby leading them to conclude that increase in emissions is dependent on fuel mechanism. Table 1 shows the leaching concentrations of metals from bagasse ash.

The chemical composition of bagasse ash reveals that it is rich in silica, alumina, and iron oxide. The chemical composition of bagasse ash reported by various researchers has been compiled in Table 2. It can be seen that the major component of the chemical composition of bagasse ash is silica. Alumina and iron oxide, though significantly lesser when compared to silica, together make up a major portion of bagasse ash composition, which contribute to pozzolanic reactions. However, the pozzolanic activity of bagasse ash depends on calcination temperature of the ash [30, 31]. According to Cordeiro et al. [30], $600^{\circ} \mathrm{C}$ for three hours is the optimal calcination condition for achieving ash of high pozzolanic activity. According to ASTM C618 [32], the minimum requirement of silica, alumina, and iron oxide for natural pozzolans is $70 \%$. It can be seen that, in almost all of the studies reported in Table 1, bagasse ash meets this requirement. Another requirement for natural pozzolan is that $\mathrm{SO}_{3}$ content should be less than $4 \%$. This criterion is also met by almost all the studies for which $\mathrm{SO}_{3}$ data has been reported. However, Pourkhorshidi et al. [33] reported that pozzolanic performance evaluated based on ASTM C618 showed disparities when compared to actual pozzolanic performance.

Mineralogical analysis of bagasse ash has also been carried out by several earlier researchers. The major mineral present in bagasse ash is quartz $[12,17,20,34]$. Bahurudeen et al. [35] reported the presence of quartz and cristobalite. 


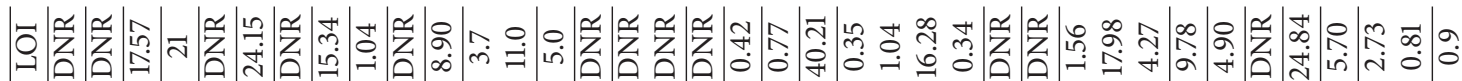

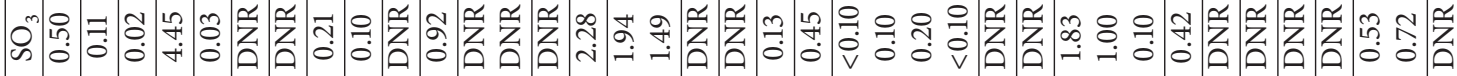
年

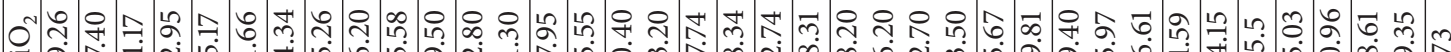

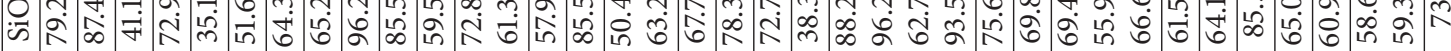

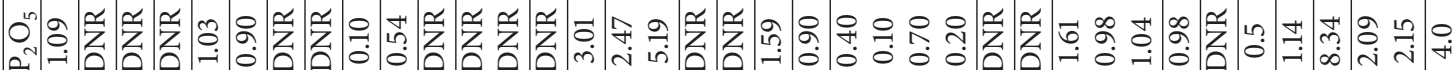

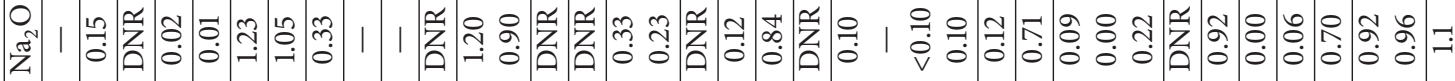

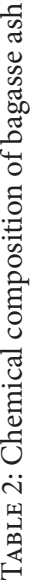
帘

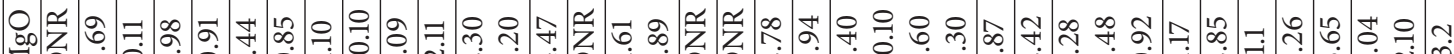

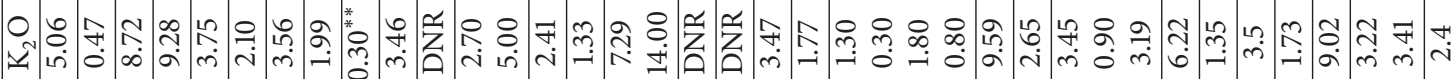

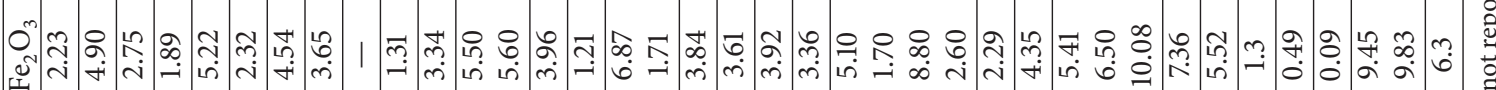

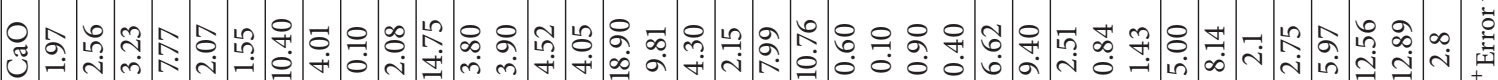

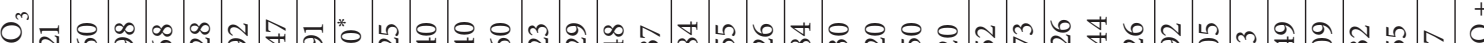

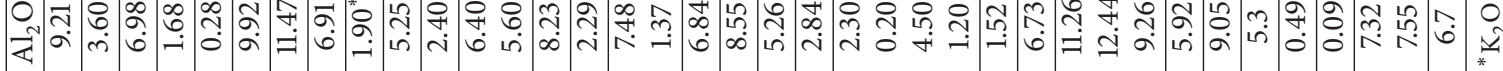

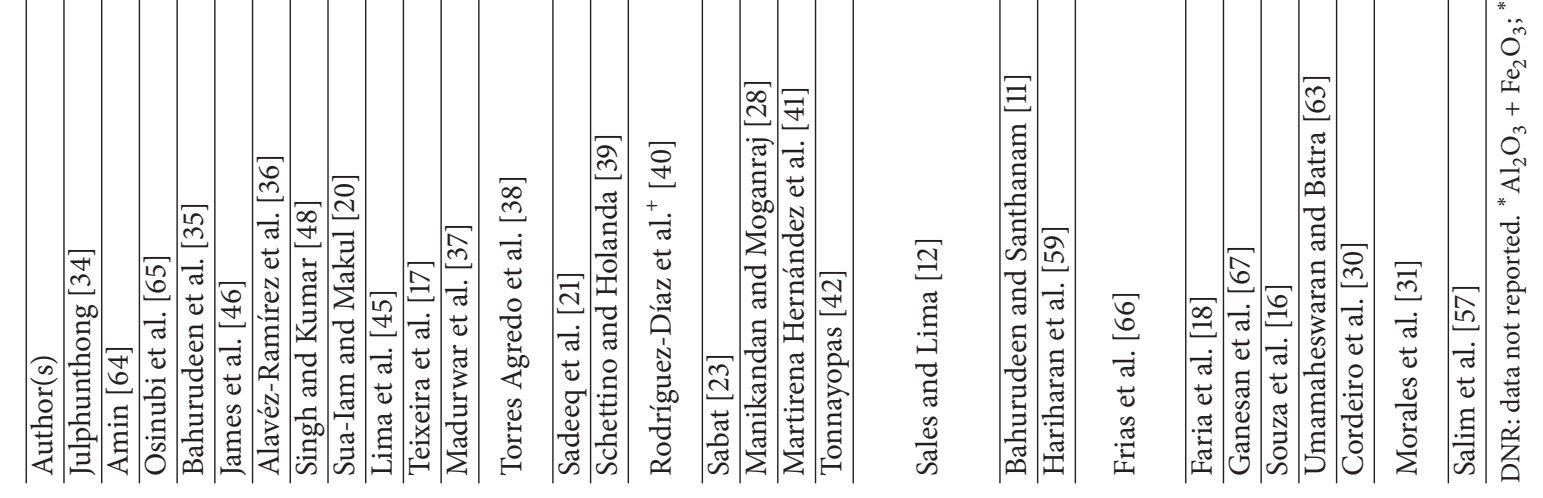


Alavéz-Ramírez et al. [36] reported the presence of carbon in addition to quartz and cristobalite. Madurwar et al. [37] reported the presence of amorphous silica in bagasse ash. Torres Agredo et al. [38] also reported the presence of calcite and ferric oxide in addition to quartz and cristobalite. Schettino and Holanda [39] reported presence of hematite, mullite, calcium phosphate, and potassium carbonate along with quartz and cristobalite. Rodríguez-Díaz et al. [40] and Martirena Hernández et al. [41] reported calcite along with quartz and cristobalite. Tonnayopas [42] found quartz, calcite, microcline, and feldspar as the major mineral components of bagasse ash. Thus, it can be seen that quartz, cristobalite, and calcite are the primary minerals present in bagasse ash with other minor varying constituents. The components of the ash can vary significantly based on the source and makeup of the material being burned [13]. Table 3 compiles the minerals identified in bagasse ash by various researchers.

Figure 1 shows the microstructure of bagasse ash reported by different investigators. It can be seen that there are instances wherein bulky crystalline particles have been recorded, whereas others reveal well burnt flakes of bagasse with small pores in the flakes of burnt bagasse fibre. Thus, the microstructure of bagasse ash is in agreement with existing literature that bagasse ash consists of both inorganic crystalline fractions as well as pyrolysed organic fractions.

\section{Bagasse Ash in Stabilized Blocks}

Solid wastes in stabilized soil blocks involve their addition to the stabilized soil matrix to achieve additional benefits in the performance of stabilized soil blocks. Valorisation of waste in this form results in combined benefits of both the primary stabilizer and the solid waste additive. This section deals with the utilization of solid wastes as additives to stabilized soil matrix.

3.1. Bagasse Ash as Auxiliary Additive in Stabilized Soil Blocks. Utilization of bagasse ash in the form of auxiliary additive involves its use in combination with a well-known primary soil stabilizer like cement or lime. This was found to be the most common form of valorisation of bagasse ash in stabilized soil blocks.

Greepala and Parichartpreecha [43] investigated the potential of utilizing fly ash, rice husk ash, and bagasse ash in the manufacture of lateritic soil-cement stabilized interlocking blocks. The authors investigated the effect of the solid wastes on the compressive strength and water absorption of the blocks. Fly ash was used to replace class I type Portland cement up to $80 \%$ by weight, while rice husk ash and bagasse ash were used to replace the same up to $50 \%$ by weight in increments of $10 \%$. The blocks were then cured for periods of 7 and 28 days. The results of the test indicated that fly ash was the best replacement for cement by mass with replacement up to $60 \%$ by weight. The strength and water absorption of the fly ash replaced block met the standards for hollow load bearing concrete masonry units.

Khobklang et al. [44] investigated the potential of bagasse ash in the replacement of cement in lateritic soil-cement
TABLE 3: Minerals present in bagasse ash.

\begin{tabular}{|c|c|}
\hline Author(s) & $\begin{array}{l}\text { Minerals identified in } \\
\text { bagasse ash }\end{array}$ \\
\hline $\begin{array}{l}\text { Teixeira et al. [17] } \\
\text { Sales and Lima[12] } \\
\text { Sua-Iam and Makul [20] } \\
\text { Julphunthong [34] } \\
\text { Souza et al. [16] }\end{array}$ & Quartz \\
\hline $\begin{array}{l}\text { Bahurudeen et al. [35] } \\
\text { Ganesan et al. [67] }\end{array}$ & Quartz, cristobalite \\
\hline Alavéz-Ramírez et al. [36] & Quartz, cristobalite, carbon \\
\hline Madurwar et al. [37] & Amorphous silica \\
\hline Torres Agredo et al. [38] & $\begin{array}{l}\text { Quartz, cristobalite, calcite, } \\
\text { ferric oxide }\end{array}$ \\
\hline Schettino and Holanda [39] & $\begin{array}{l}\text { Quartz, cristobalite, } \\
\text { potassium carbonate, } \\
\text { calcium phosphate, } \\
\text { hematite, mullite }\end{array}$ \\
\hline $\begin{array}{l}\text { Rodríguez-Díaz et al. [40] } \\
\text { Martirena Hernández et al. [41] }\end{array}$ & Quartz, cristobalite, calcite \\
\hline Tonnayopas $[42]$ & $\begin{array}{l}\text { Quartz, calcite, microcline, } \\
\text { feldspar }\end{array}$ \\
\hline James and Pandian [47] & $\begin{array}{l}\text { Quartz, cristobalite, } \\
\text { calcium carbonate }\end{array}$ \\
\hline Aigbodion et al. [60] & $\begin{array}{l}\text { Quartz, cliftonite, } \\
\text { moissanite, titanium } \\
\text { dioxide }\end{array}$ \\
\hline Frias et al. [66] & $\begin{array}{l}\text { Quartz, iron oxide, } \\
\text { graphite, mullite, kaolinite, } \\
\text { cristobalite, gibbsite }\end{array}$ \\
\hline Faria et al. [18] & $\begin{array}{l}\text { Quartz, cristobalite, } \\
\text { hematite, mullite, calcium } \\
\text { phosphate, potassium } \\
\text { carbonate }\end{array}$ \\
\hline Umamaheswaran and Batra [63] & Quartz, calcite \\
\hline
\end{tabular}

interlocking blocks. Portland cement was replaced with $15 \%, 30 \%$, and $40 \%$ bagasse ash and mixed with lateritic soil, sand, and water for moulding the blocks followed by curing for a period of 90 days. The test results revealed that $15 \%$ bagasse ash produced the highest compressive strength when compared to the other replacement contents. It was found that the addition of bagasse ash increased the water absorption of the blocks. However, an increase in the water to binder ratio was found to reduce water absorption.

Alavéz-Ramírez et al. [36] investigated the effect of bagasse ash on the durability of lime stabilized soil blocks. Blocks were prepared with $10 \%$ lime and combination of $10 \%$ lime with $10 \%$ sugarcane bagasse ash and cured for 7,14 , and 28 days of curing. The stabilized blocks were then subjected to compression and flexure tests in both dry and saturated states. The tests revealed that addition of bagasse ash to lime stabilized blocks significantly improved the performance of the stabilized blocks. Mineralogical and microstructural investigations were also carried out which revealed a considerable improvement in the stabilized soil matrix due to the formation of $\mathrm{CSH}$ and $\mathrm{CAH}$ phases. 

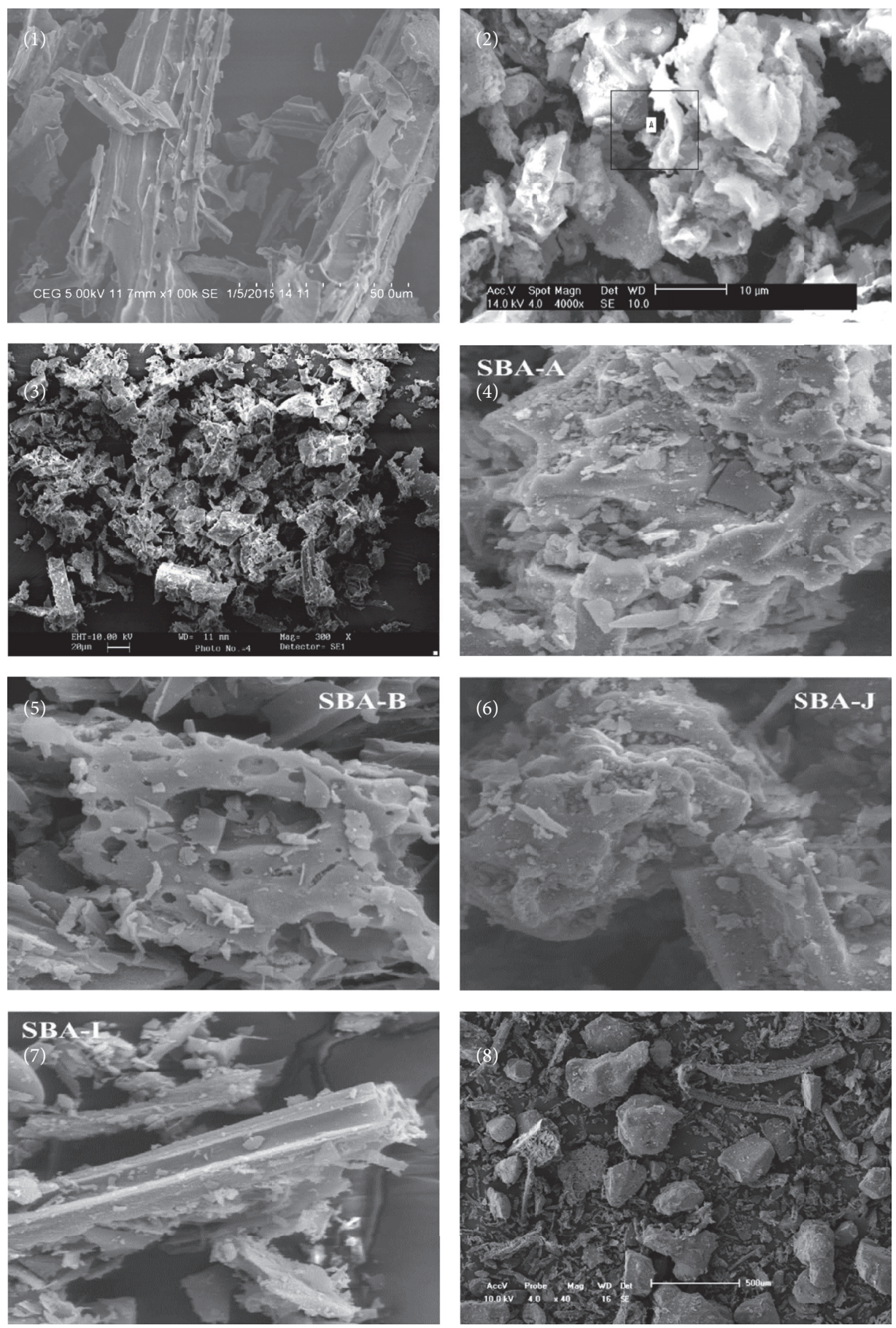

Figure 1: Microstructure of sugarcane bagasse ash (source: (1) James and Pandian [47], (2) Aigbodion et al. [60], (3) Umamaheswaran and Batra [63], (4, 5, 6, and 7) Sales and Lima [12], and (8) Faria et al. [18]).

Lima et al. [45] investigated the potential of modified cement stabilized soil blocks amended with bagasse ash. Two cement contents of $6 \%$ and $12 \%$ were adopted for making the blocks which were amended with $2 \%, 4 \%$, and $8 \%$ bagasse ash. Compressive strength and water absorption tests were performed on the stabilized blocks. Masonry prisms were also prepared with the stabilized blocks for testing. The blocks produced with $12 \%$ cement amended with $8 \%$ bagasse ash met the standards for stabilized blocks. The prisms made with modified blocks also produced better performance in axial and diagonal compression tests when compared to blocks without ash.

James et al. [46] investigated the effect of bagasse ash on the potential of cement stabilized soil blocks. Two different cement contents of $4 \%$ and $10 \%$ were adopted for stabilizing the soil blocks which were amended by $4 \%, 6 \%$, and $8 \%$ 
bagasse ash. The blocks were all cast to one particular unit weight and moisture content. The blocks were subjected to compressive strength, water absorption, and efflorescence tests. The results of the investigation revealed that addition of bagasse ash resulted in an increase in the performance of the blocks with increased compressive strength and no efflorescence. Addition of bagasse ash resulted in lower cement content of $4 \%$ being capable of achieving minimum strength requirements as per standards. However, there was a marginal increase in the water absorption due to addition of bagasse ash. It was also concluded that bagasse ash performed better at lower cement content of $4 \%$ when compared to $10 \%$.

James and Pandian [47], in an extension of their earlier work, evaluated the potential of bagasse ash in improving the performance of lime stabilized blocks. The minimum lime content required for stabilizing a locally available soil was determined using the Eades and Grim $\mathrm{pH}$ test. The initial consumption of lime was found out to be $6 \%$. The soil was stabilized with $6 \%$ lime and amended with $4 \%$ to $8 \%$ bagasse ash in increments of $2 \%$. They found that the addition of bagasse ash resulted in an increase in the compressive strength of the stabilized block and increased the water absorption of the block. $8 \%$ bagasse ash produced the maximum strength but was not enough to meet the minimum strength of class 20 block as per Indian standards. The authors attempted to develop a relationship between the compressive strength and bagasse ash content, based on which they concluded a minimum requirement of $9.5 \%$ bagasse ash for achieving strength of class 20 block.

Singh and Kumar [48] adopted combinations of cement, sand, and bagasse ash for manufacture of light weight bricks. Bagasse ash was adopted in proportions between 15\% and $35 \%$ in increments of 5\% with sand and 20\% cement. The combinations were adopted for casting bricks of nonmodular size of $225 \mathrm{~mm} \times 110 \mathrm{~mm} \times 70 \mathrm{~mm}$ and cured, followed by tests for compressive strength, water absorption, and efflorescence. The combination with $15 \%$ bagasse ash with $20 \%$ cement produced the highest strength of all combinations. All combinations produced strength higher than the minimum strength required for a class 30 block.

Kulkarni et al. [49] investigated the capability of bagasse ash in fly ash bricks as a replacement for fly ash as well as lime. Bricks of size of $230 \mathrm{~mm} \times 100 \mathrm{~mm} \times 75 \mathrm{~mm}$ were manufactured with various combinations, wherein bagasse ash was used to replace fly ash up to $60 \%$ and lime up to $20 \%$ by weight in increments of $10 \%$ and $5 \%$, respectively. The bricks were then tested for compressive strength and water absorption after curing periods of 7, 14, and 21 days. It was found that replacement of fly ash with bagasse ash resulted in a reduction in strength of the stabilized block with increase in bagasse ash content. However, all combinations produced strength higher than the minimum, required for class 30 blocks. It was found that $10 \%$ bagasse ash as replacement for fly ash produced the strength closest to that of control specimen with the strength variation being less than $5 \%$.

Madurwar et al. [37] analysed the potential of bagasse ash in enhancing the performance of quarry dust-lime stabilized blocks. The chemical composition of the materials was analysed using X-ray florescence tests. Thermogravimetric analysis was performed on bagasse ash which revealed that it was stable till a temperature of $650^{\circ} \mathrm{C}$. Scanning electron microscopy was used to study the microstructure of bagasse ash which showed numerous fine pores in the individual particles. The blocks consisted of $20 \%$ lime by weight, while bagasse ash was varied from $50 \%$ to $80 \%$ and quarry dust was varied from $30 \%$ to $0 \%$ in increments of $5 \%$. The blocks were cast to a size of $230 \mathrm{~mm} \times 110 \mathrm{~mm} \times 80 \mathrm{~mm}$ and cured. They were then tested for their compressive strength, water absorption, and efflorescence. The test programme also included results from testing of a conventional brick and a fly ash brick. The results of the test revealed that 50\% bagasse ash with 30\% quarry dust and 20\% lime produced the highest of compressive strengths of all combinations. This combination was also subjected to advanced physicomechanical tests including flexural strength, shear bond, combined compressive, and modified bond strength tests. The water absorption of bagasse ash bricks was higher than conventional and fly ash bricks. No efflorescence was detected on any of the bagasse ash brick combinations.

Priyadarshini [50] investigated the effect of replacing cement in hollow concrete blocks with bagasse ash and silica fumes as admixture. The test programme investigated two mix ratios of concrete in which bagasse ash was used to replace cement up to $30 \%$ by weight with silica fumes as admixture. The cast hollow blocks were then subjected to compressive strength and water absorption tests. At the end of the test programme, the author concluded that up to $10 \%$ replacement with bagasse ash with silica fume admixture was found to produce performance close to the control specimens. The author also performed a cost analysis, based on which she concluded that using bagasse ash as replacement in concrete hollow blocks can achieve a profit ratio on sales of up to $63.7 \%$.

Rajkumar et al. [51] investigated the use of bagasse ash paver blocks on low traffic road pavements. The investigation consisted of designing and testing four trial mixes with bagasse ash in accordance with BIS and IRC standards. This was followed by design of a flexible pavement for low volume traffic roads. The paver blocks were designed with $50 \%$ bagasse ash addition in the mix. The compressive strength results of the paver blocks as well as cubes revealed that though the strength of the paver blocks with bagasse ash was lower than the control specimens, the strength values were very close to the control. The design of pavement with bagasse ash paver blocks was cheaper than conventional flexible pavement by $24.15 \%$. The authors also cite higher design life for bagasse ash paver block pavement as well as reduced maintenance costs when compared to conventional flexible pavement.

Naibaho et al. [52] investigated the utilization of bagasse ash in reducing the cement content of stabilized bricks. Three bagasse ash contents of 5\%, $15 \%$, and $25 \%$ were investigated for their performance in increasing the compressive strength and reducing water absorption in achieving a cost-effective stabilized brick. The test results revealed that the addition of $25 \%$ bagasse ash produced the highest compressive strength but resulted in an increase in water absorption. The authors concluded that utilization of $25 \%$ bagasse ash in manufacture 
of cement stabilized bricks decreased the production costs by $32.48 \%$.

Ali et al. [53] investigated the effect of bagasse ash on the strength of compressed cement stabilized earth blocks. The soil was amended with $20 \%, 25 \%$, and $30 \%$ bagasse ash as a partial replacement for cement and was cured for periods of 7 days and 28 days. The soil blocks were then subjected to initial rate absorption, density, dimensions, compressive strength, and water absorption tests. $20 \%$ bagasse ash was found to be the optimum replacement content for cement in the manufacture of compressed stabilized blocks. The water absorption increased on addition of bagasse ash; however, the increase stabilized beyond $20 \%$ bagasse addition. The weight of the block reduced marginally due to the addition of bagasse ash. The authors concluded that further studies on energy consumption and chemical properties need to be conducted before bagasse ash can be adopted in brick manufacture.

Onchiri et al. [54] investigated the partial replacement of cement in self-interlocking blocks with bagasse ash. Silty gravel soil was stabilized using cement and it was amended with bagasse ash with mix proportions of $1.6 \%, 3.2 \%, 4.8 \%$, $6.4 \%$, and $8 \%$. The stabilized blocks were then cured for periods of 7 days and 28 days. The results of the compressive strength tests revealed that the maximum compressive strength was achieved at an additive content of $3.2 \%$. The authors concluded that bagasse ash to cement in the ratio of $1: 1.5$ was the optimal dosage as it met the minimum standards for compressed stabilized blocks.

3.2. Bagasse Ash Stabilized Soil Blocks. Bagasse ash has also been used in the manufacture of stabilized earth bricks as standalone stabilizers. The use of primary stabilizers like cement and lime is avoided, while bagasse ash forms the primary stabilizer in their place.

Saranya et al. [55] investigated combinations of bagasse ash and rice husk ash in development of stabilized bricks without any other conventional binder. The investigation involved combinations of bagasse ash and rice husk ash in equal proportions varying from $5 \%$ till $30 \%$ in increments of $5 \%$. The bricks were tested for their compressive strength and water absorption and checked for density of the cast brick for various combinations. The test programme revealed that $5 \%$ bagasse ash with $5 \%$ rice husk ash produced the highest strength of all combinations. The water absorption of the blocks also increased with increase in waste content. The authors recommended the combination of bagasse ash and rice husk ash up to $20 \%$ in manufacture of the brick with additional advantage of the bricks being their light weight nature.

Prasanth et al. [56] investigated the performance of pressed composite bricks made with different additives including bagasse ash, fly ash, jaggery, quarry dust, lime, and cement. The additives were all added individually and the strength of the composite brick was tested. It was found that $10 \%$ cement gave the highest strength of all combinations. However, it was also found that $5 \%$ bagasse ash composite earth brick gave strength close to that of $10 \%$ lime stabilized earth brick.

Salim et al. [57] investigated the potential of bagasse in the manufacture of sandy loam soil compressed earth block.
Sandy loam soil was adopted for the manufacture of the blocks and they were amended with $3 \%, 5 \%, 8 \%$, and $10 \%$ bagasse ash and were compressed and cast into blocks of $285 \mathrm{~mm} \times 145 \mathrm{~mm} \times 95 \mathrm{~mm}$ blocks and cured for periods of 14,21 , and 28 days. Following the curing periods, they were subjected to compressive strength test and shrinkage crack test. The results showed that $10 \%$ bagasse ash was able to increase the strength of sandy loam soil block by $65 \%$. There was also a $7 \%$ reduction in the shrinkage cracks of $10 \%$ bagasse ash amended soil blocks.

3.3. Bagasse Ash Amended Sintered Blocks/Tiles. While the valorisation of bagasse ash has been the primary focus of this paper, there have also been instances wherein bagasse ash has been utilized in the manufacture of sintered blocks as well. However, sintering of blocks consumes energy which is the primary reason for opting for stabilized soil blocks. But a look into the performance of bagasse ash in sintered bricks is worthwhile to understand its role in enhancing their properties, wherein strength gain is through an altogether different mechanism. This will also serve as a cornerstone for further future research in the area.

Tonnayopas [42] investigated the potential of bagasse ash as an additive in the manufacture of sintered bricks. The bagasse ash content was varied from 10 to $15 \%$ by weight of clay used in the manufacture of the brick. As against a conventional stabilized soil block, this investigation involved utilization of bagasse ash in sintered bricks, wherein the modified bricks were fired at a temperature of $1050^{\circ} \mathrm{C}$. Bagasse ash was characterized using X-ray fluorescence, $\mathrm{X}$-ray diffraction, and thermogravimetric analyses. The sintered bricks were subjected to compressive strength, water absorption, and density tests. The microstructures of the failed brick specimens were also studied using scanning electron microscopy. The investigation revealed that addition of bagasse ash affected even the performance of sintered bricks with $30 \%$ bagasse ash producing the highest compressive strength of close to $43 \mathrm{MPa}$. Water absorption of all combinations till $30 \%$ bagasse ash content was less than $15 \%$. The authors concluded that $30 \%$ bagasse ash by weight of clay can be used for forming the brick sintered at a temperature of $1050^{\circ} \mathrm{C}$.

Teixeira et al. [17] looked into the potential of replacing quartz with bagasse ash in red ceramic. Bagasse ash was characterized using X-ray fluorescence and X-ray diffraction tests. Prismatic probes of ceramic material amended with bagasse ash in quantities of $5 \%, 8 \%$, and $10 \%$ by weight were fired at temperatures between $800^{\circ} \mathrm{C}$ and $1200^{\circ} \mathrm{C}$. The fired ceramic probes were tested for texture, flexural strength, and shrinkage. The results showed that the addition of bagasse ash as replacement for quartz resulted in a reduction in flexural strength and increase in shrinkage with sintering temperature. However, the authors concluded that the amount of ash that can be incorporated will depend on both the composition of the clay and the ash to be incorporated. In their study, they recommended that up to $10 \%$ of bagasse ash can be incorporated in red ceramic.

Schettino and Holanda [58] examined the effect of addition of bagasse ash in the processing of porcelain stoneware. The bagasse ash waste was increased from 0 to $5 \%$ through 
$1.25 \%$ and $2.5 \%$. The formulation consisted of kaolin clay, sodium feldspar, quartz, and bagasse ash with bagasse ash forming the replacement for quartz in various combinations. The tile formulations were then fired in a fast firing kiln at $1230^{\circ} \mathrm{C}$ for less than 60 minutes. The tiles were then subjected to mineralogical, microstructural investigations through $\mathrm{X}$ ray diffraction and scanning electron microscopy. The tiles were also subjected to linear shrinkage, apparent density, water absorption, and flexural strength tests. The increase in bagasse ash content resulted in an increase in linear shrinkage as well as water absorption and reduction in flexural strength. However, bagasse ash content up to $2.5 \%$ resulted in water absorption and flexural strength that met the minimum requirements for porcelain tiles. Thus, the authors concluded that up to $2.5 \%$ bagasse ash can be used in the manufacture of porcelain stoneware with good technical properties.

Hariharan et al. [59] investigated the preparation and characterization of ceramic products with sugarcane bagasse ash waste. Tile compositions of $50 \%$ clay, $15 \%$ quartz, and $35 \%$ feldspar were obtained from a local manufacturer and sugarcane bagasse ash was used as a replacement for feldspar. The amended composition included 20\% bagasse ash in lieu of feldspar, whose composition was reduced to $15 \%$ of the total. Two different porcelain insulators were prepared using the above-mentioned combinations by firing them. The manufactured ceramic specimens were subjected to porosity, water absorption, bulk density, and dielectric strength properties. The morphology of the prepared specimens was also studied using scanning electron microscopy. The bagasse ash amended porcelain insulator showed a reduction in water absorption and porosity and an increase in its bulk density and dielectric strength. The microstructure revealed a reduction in pores and revealed a denser matrix with the advent of vitrification.

Aigbodion et al. [60] investigated the potential of utilization of bagasse ash in industry. They prepared bagasse ash by calcining it at a temperature of $1200^{\circ} \mathrm{C}$ for 5 hours to obtain bagasse ash. The ash was then mixed with gum Arabic and water for enhancing its plasticity, following which the mix was pressed into moulds using a hydraulic jack under a pressure of $9 \mathrm{~kg} / \mathrm{cm}^{2}$. It was then air-dried followed by oven drying at $110^{\circ} \mathrm{C}$ for removal of moisture. The moulded bricks were then fired at various temperatures ranging from $200^{\circ} \mathrm{C}$ to $1400^{\circ} \mathrm{C}$ in a digital electric furnace. The fired specimens were then tested for firing shrinkage, density, and refractoriness. The evaluation revealed that fired bricks made of bagasse ash and gum Arabic had very low firing shrinkage, were light in weight (density of the order of carbon and silica), and were highly refractory, capable of withstanding temperatures up to $1600^{\circ} \mathrm{C}$.

Faria et al. [18] investigated the potential of using bagasse ash as raw material in the manufacture of clay bricks. The waste material was characterized by its chemical composition, mineralogy, thermal stability, morphology, particle size, and pollution potential. Bagasse ash was used to replace clay by $20 \%$ and bricks were prepared and fired at a temperature of $1000^{\circ} \mathrm{C}$ in an electrical kiln. The bricks were then evaluated for their linear shrinkage, water absorption, apparent density, and tensile strength. It was found that the addition of bagasse ash waste to clay in brick formulations resulted in a reduction in tensile strength, increase in water absorption, and reduction in linear shrinkage and density of the bricks. The authors concluded that up to $10 \%$ bagasse ash waste can be incorporated in the manufacture of clay bricks from the point of view of environmental protection, waste management, and saving of raw materials.

Teixeira et al. [61] investigated the manufacture of wollastonite based glass ceramic using bagasse ash as raw material. The glasses were prepared by mixing bagasse ash, limestone, and potassium carbonate as flux. The mixtures were melted at $1400^{\circ} \mathrm{C}$ using a lift oven, poured into water to form glass frits, dried, milled, and sieved for mineral and thermal analysis. They were then moistened with ethylene glycol and pressed into pellets with a hydraulic press. These pellets were then sintered at varying temperatures to crystalize and vitrify them. The glass ceramics were produced with two different combinations of bagasse ash and limestone. It was concluded that valorisation of bagasse ash in the manufacture of glass ceramics can result in production of wollastonite based ceramics at lower crystallization temperatures of less than $900^{\circ} \mathrm{C}$, which significantly reduces production costs.

As mentioned earlier, the effectiveness of utilization of bagasse ash as a pozzolan will depend upon the purity of the ash, reactiveness of the silica, and pretreatment of ash, if any, to improve its reactivity. Thus, in order to compare all the investigations adopting bagasse ash in stabilized blocks, a comparative table has been generated comparing the temperature of burning or calcination temperature of the ash, which plays a predominant role in the quality of the ash, the loss on ignition, which gives an indication of volatile impurities present, the type of silica present in the ash, crystalline or amorphous based on the details given in the mineralogical investigations by the authors, and, lastly, the treatment/preparation of the ash done before its use in the investigation. The comparison is shown in Table 4.

It can be seen that a majority of the authors either have not considered or have not reported all or most of the important parameters that affect the quality of the ash and hence its pozzolanic activity. However, a few authors have reported at least three of the four criteria considered in this work. Though there is a significant number of investigations reporting the performance of bagasse ash as a pozzolanic additive in stabilized/sintered blocks or tiles, most of them do not report important criteria that can be used to understand the performance achieved in their investigations. Thus, this is a major shortfall in existing literature which needs to be addressed in all future investigations, wherein any investigation planning the use of bagasse ash, as a pozzolanic additive, reports the important parameters considered here to enable the investigators as well as end users to understand and replicate, if necessary, the work done, at a future date. The data provided by the few authors who have reported the important criteria provides a sound foundation for all future investigations.

3.4. An Evaluative Discussion. Table 5 shows the performance of bagasse ash in stabilized/sintered soil blocks/tiles. It can be seen that a variety of block sizes has been investigated by various researchers. However, there are no clear-cut 


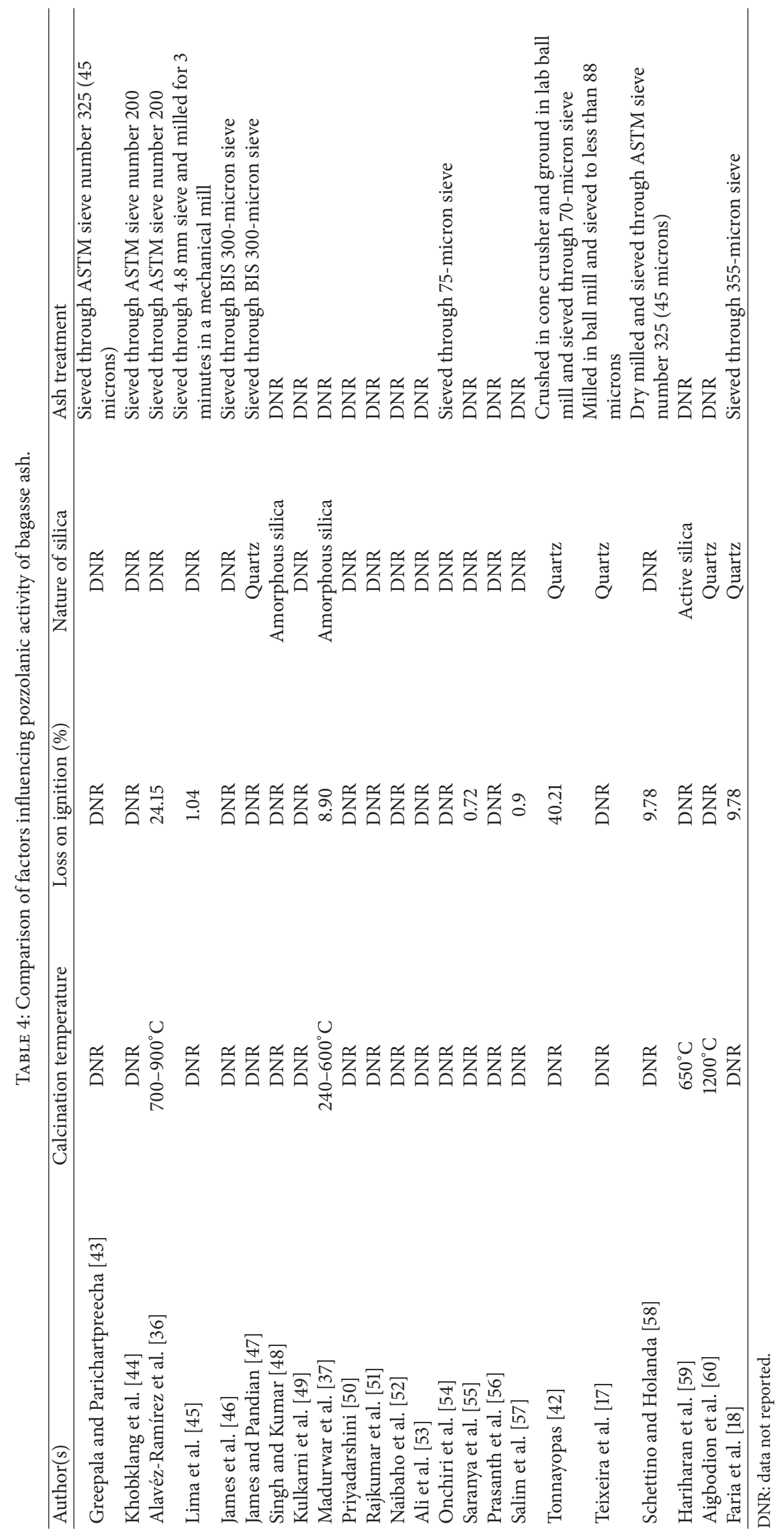




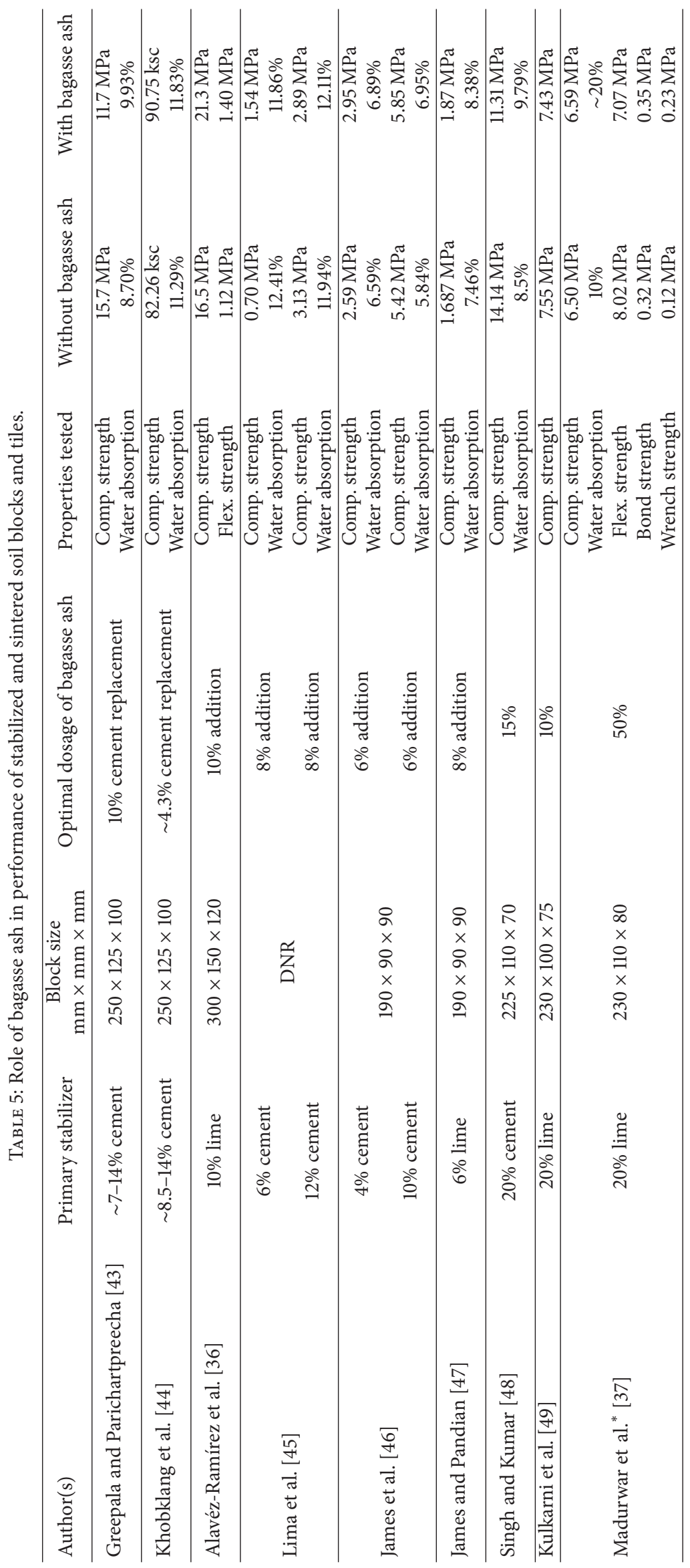




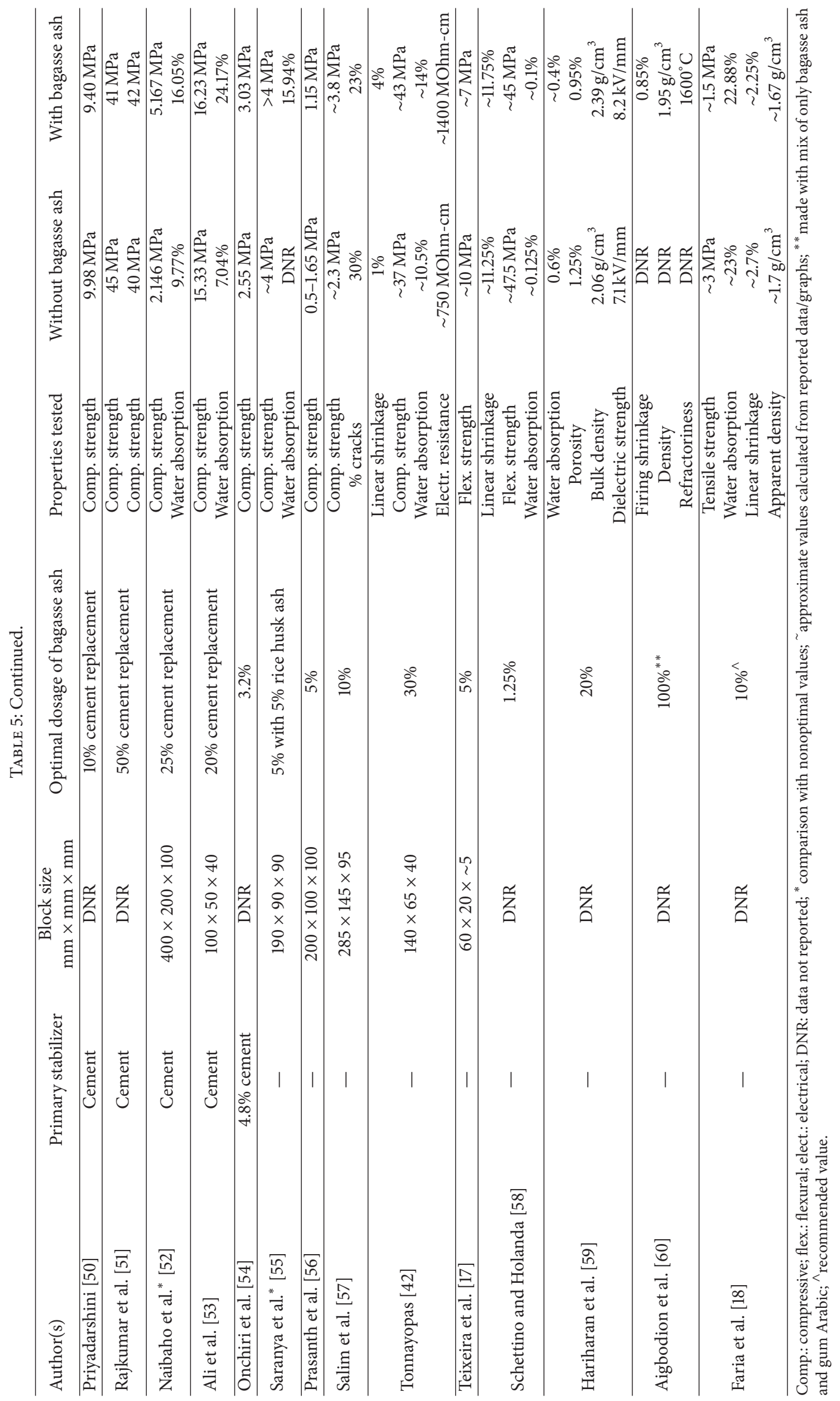


common dimensions that have been preferred by the various researchers with wide variations in sizes. Predominantly, investigations have been based on determination of compressive strength and water absorption only. Efflorescence has been attempted by some of the researchers. However, BIS code [62] for stabilized soil blocks also recommends a weathering test for stabilized soil blocks. The test is intended to evaluate the loss in weight of the stabilized block on being subject to a water spray essentially testing the durability of the stabilized blocks subjected to water erosion. However, in the reviewed literature, the authors could not find such a test being performed to evaluate the durability of the stabilized blocks. One instance of evaluation of modified strength like combined compressive strength, modified wrench test, and bond strength tests was found in the work done by Madurwar et al. [37]. Salim et al. [57] had performed a failure analysis in their loading tests, based on which a percentage crack development on failure was done. Bagasse ash has been predominantly utilized as auxiliary additive to cement or lime rather than a standalone stabilizer which may be due to the lower level of strength gains achieved when bagasse ash alone is used for stabilizing the blocks. The use of bagasse ash in sintered blocks and tiles has also been reported by a few. Looking at the results of the compressive strength of bagasse ash amended stabilized blocks, barring a few works that have reported a negative result due to the addition of bagasse ash; the rest have all reported positive strength outcomes. Even those works that had reported negative results pointed out that the strengths achieved by bagasse ash addition though were lesser than the control specimen; they were still higher than the minimum standard strength and hence focused on the cost reduction achieved while maintaining the strength for practical usage. In some of the investigations, the reduction in strength was due to the replacement of cement by bagasse ash which led to a reducing cement content with increasing ash content leading to strength decrease. Virtually all investigations agreed that bagasse ash amendment led to an increase in the water absorption of the stabilized blocks. Effect of bagasse ash on sintered blocks and tiles has been studied by a few researchers, wherein there is a reduction in the flexural strength in the case of tiles but still they are above the minimum requirement as per the relevant standards and hence the authors, despite a reduction in strength, do recommend the valorisation of bagasse ash in sintered tiles as well. More detailed research in the utilization of bagasse ash in sintered tiles can open up a new line of research for increased valorisation of bagasse ash in other sintered products.

Understanding the cost economy achieved by valorisation of bagasse ash is another important aspect that can enhance the utilization of this waste in Civil Engineering materials, thereby achieving sustainable waste management. The cost economy achieved by bagasse ash can be either by savings in raw material or in the form of savings due to process optimization. Kulkarni et al. [49] reported that valorisation of bagasse ash in stabilized blocks resulted in a cost of Rs. $2420 / 1000$ blocks against a cost of Rs. $4000 / 1000$ conventional clay bricks. This works out to savings of $39.5 \%$ in cost per brick. However, Priyadarshini [50] reported a profit on sales ratio of $63.7 \%$ achieved due to manufacture and sale of bagasse ash concrete blocks. Rajkumar et al. [51] reported cost savings of $24.15 \%$ due to valorisation of bagasse ash in the manufacture of paver blocks for low volume traffic roads. Utilization of bagasse ash can also optimize the process operation, thereby achieving cost economy from other means of operations. Teixeira et al. [61] report that the utilization of bagasse ash in the manufacture of sintered glass ceramics can be achieved at significantly lower temperatures of less than $900^{\circ} \mathrm{C}$, thereby significantly reducing the costs involved in sintering of blocks to produce ceramics.

\section{Conclusions}

The paper was aimed at giving an overview of the characterization and utilization of bagasse ash in manufacture of stabilized blocks and tiles. Based on the review of literature that concentrated on the utilization of bagasse ash in the manufacture of blocks and tiles, the following points can be concluded:

(i) Bagasse ash is a solid waste of economic importance which is produced as a by-product from the sugar manufacturing industry in huge quantities. Bagasse ash consists of both bottom ash collected from the boilers and fly ash collected from the gas washers. The ashes are composed of both organic and inorganic fractions but fly ash consists of more organic content compared to bottom ash. India is one of the leading producers of sugar; this waste is generated in huge quantities in India leading to potential disposal problems without effective management techniques. However, the economic importance of this solid waste has been realised with several applications like adsorbents, filters, ceramics, briquettes, bricks, and blocks and soil amendment activities.

(ii) A lot of researchers have attempted to characterize this solid waste and have more or less concluded that it is a waste material that is rich in silica and can contribute to pozzolanic reactions due to the high amounts of silica, alumina, and iron oxide present in it, a requirement stipulated by ASTM for natural pozzolans. The pozzolanic activity of the ash depends on the presence of amorphous silica rather than crystalline silica, which is dependent on the temperature of calcination of the ash. Pretreatment of the ash by sieving or milling can reduce its particle size and, hence, improve its reactivity. Mineralogical characterization has revealed that bagasse ash is predominantly composed of quartz and cristobalite, both of which are silica minerals, followed by calcite which is agreed upon by most of the researchers. Other minerals reported vary with the source of the ash. Microstructure of bagasse ash from various sources reveals both crystalline forms and flakes of individual burnt fibres with pores, which is in agreement with the fact that bagasse ash consists of both organic and inorganic crystalline fractions. 
(iii) Bagasse ash utilization in soil engineering activities has increased in recent times with it gaining prominence in stabilized soil blocks. The utilization of bagasse ash in soil blocks has been adopted in two modes as auxiliary additive/replacement to primary stabilizers like lime or cement or as standalone stabilizer/additive to soil in the manufacture of blocks. The common tests adopted in investigations dealing with stabilized soil blocks include compressive strength, water absorption, and to a lesser extent efflorescence of blocks.

(iv) The available literature reveals that addition of bagasse ash results in an improvement in the strength of stabilized blocks in most of the cases. Addition of bagasse ash to cement as auxiliary additive results in an enhanced performance of the stabilized blocks. However, it has been reported that bagasse ash performs better at lower cement contents when compared to higher cement contents. When bagasse ash is added as standalone stabilizer in manufacture of blocks, it results in an improved performance when compared to unstabilized blocks but their performance is lower when compared to cement/lime stabilized blocks amended with bagasse ash. Virtually, all of the investigations reviewed reported an increase in the water absorption of the stabilized blocks due to addition of bagasse ash. In some cases, the water absorption levels of bagasse ash amended stabilized soil blocks were higher than those recommended by Bureau of Indian Standards.

(v) A lot of researchers have worked on the compressive strength and water absorption of the stabilized blocks. However, stabilized soil blocks have been known to be less durable. Thus, durability of stabilized blocks is an important aspect that needs to be concentrated upon to increase the acceptability of stabilized blocks in practice. Bureau of Indian Standards recommends a weathering test for investigating the durability of stabilized blocks, which does not find any place in the research works reviewed. Apart from this, other types of tests have been studied but minimally include bond test, flexure test, and wrench tests on stabilized block masonry. More investigations concentrating on the durability of the stabilized blocks can improve the acceptability of stabilized blocks and the role of bagasse ash in improving the durability properties can be revealed better.

(vi) Addition of bagasse ash to sintered blocks and tiles has generally resulted in a reduction in the flexural strength of tiles/blocks. However, the reduced strength was still higher than minimum requirements as per relevant standards. The utilization of bagasse ash in sintered blocks opens up one more avenue for valorisation of bagasse ash due to its thermal stability. More investigations on the thermal and electrical properties of bagasse ash amended sintered blocks will reveal its full potential. (vii) The valorisation of bagasse ash has been found to reduce cost either in the form of savings in raw material when adopted in stabilized/sintered products or in the form of savings due to process optimization in the case of sintered tiles/blocks. A more detailed reporting of cost economy achieved due to valorisation of bagasse ash by future investigators can help in mainstreaming the utilization of bagasse ash in manufacture of stabilized/sintered blocks for spurring growth in the manufacture of low cost construction materials.

Thus, it can be seen that bagasse ash is a silica rich material that can contribute to improving the performance of stabilized soil blocks while still having unrealised potential in further making stabilized/sintered soil blocks more durable and acceptable for use in commercial applications.

\section{Competing Interests}

The authors declare that there are no competing interests regarding the publication of this article.

\section{References}

[1] P. J. Walker, "Strength, durability and shrinkage characteristics of cement stabilised soil blocks," Cement and Concrete Composites, vol. 17, no. 4, pp. 301-310, 1995.

[2] E. A. Adam and A. R. A. Agib, "Compressed stabilized earth block manufacture in Sudan," 2001, http://unesdoc.unesco.org/ images/0012/001282/128236e.pdf.

[3] J. James and P. K. Pandian, "Soil stabilization as an avenue for reuse of solid wastes: a review," Acta Technica Napocensis: Civil Engineering \& Architecture, vol. 58, no. 1, pp. 50-76, 2015.

[4] J. James and P. K. Pandian, "Industrial wastes as auxiliary additives to cement/lime stabilization of soils," Advances in Civil Engineering, vol. 2016, pp. 1-17, 2016.

[5] F. O. Okafor and D. E. Ewa, "Predicting the compressive strength of obudu earth blocks stabilized with cement kiln dust," Nigerian Journal of Technology, vol. 31, no. 2, pp. 149-155, 2012.

[6] C. Vijayaraghavan, J. James, and S. Marithangam, "Cost effective bricks in construction: a performance study," International Journal of Applied Engineering Research (IJAER), vol. 4, no. 3, pp. 227-234, 2009.

[7] E. B. Oyetola and M. Abdullahi, "The use of rice husk ash in low-cost sandcrete block production," Leonardo Electronic Journal of Practices and Technologies, vol. 5, no. 8, pp. 58-70, 2006.

[8] F. Adogla, P. Paa, K. Yalley, and M. Arkoh, "Improving compressed laterite bricks using powdered eggshells," International Journal of Engineering Science, vol. 5, no. 4, pp. 65-70, 2016.

[9] L. Ajam, M. Ben Ouezdou, H. S. Felfoul, and R. E. Mensi, "Characterization of the Tunisian phosphogypsum and its valorization in clay bricks," Construction and Building Materials, vol. 23, no. 10, pp. 3240-3247, 2009.

[10] N. Degirmenci, "The using of waste phosphogypsum and natural gypsum in adobe stabilization," Construction and Building Materials, vol. 22, no. 6, pp. 1220-1224, 2008.

[11] A. Bahurudeen and M. Santhanam, "Performance evaluation of sugarcane bagasse ash-based cement for durable concrete," in 
Proceedings of the 4th International Conference on the Durability of Concrete Structures (ICDCS '14), pp. 275-281, July 2014.

[12] A. Sales and S. A. Lima, "Use of Brazilian sugarcane bagasse ash in concrete as sand replacement," Waste Management, vol. 30, no. 6, pp. 1114-1122, 2010.

[13] S. R. Teixeira, A. E. De Souza, A. Fidel, and V. Peña, "Use of charcoal and partially pirolysed biomaterial in fly ash to produce briquettes: sugarcane bagasse," in Alternative Fuel, M. Manzanera, Ed., p. 346, InTech, Rijeka, Croatia, 2011.

[14] M. Balakrishnan and V. S. Batra, "Valorization of solid waste in sugar factories with possible applications in India: a review," Journal of Environmental Management, vol. 92, no. 11, pp. 28862891, 2011.

[15] S. R. Teixeira, A. E. Souza, C. L. Carvalho, V. C. S. Reynoso, M. Romero, and J. M. Rincón, "Characterization of a wollastonite glass-ceramic material prepared using sugar cane bagasse ash (SCBA) as one of the raw materials," Materials Characterization, vol. 98, pp. 209-214, 2014.

[16] A. E. Souza, S. R. Teixeira, G. T. A. Santos, F. B. Costa, and E. Longo, "Reuse of sugarcane bagasse ash (SCBA) to produce ceramic materials," Journal of Environmental Management, vol. 92, no. 10, pp. 2774-2780, 2011.

[17] S. R. Teixeira, A. E. De Souza, G. T. De Almeida Santos, A. F. V. Peña, and Á. G. Miguel, "Sugarcane bagasse ash as a potential quartz replacement in red ceramic," Journal of the American Ceramic Society, vol. 91, no. 6, pp. 1883-1887, 2008.

[18] K. C. P. Faria, R. F. Gurgel, and J. N. F. Holanda, "Recycling of sugarcane bagasse ash waste in the production of clay bricks," Journal of Environmental Management, vol. 101, pp. 7-12, 2012.

[19] K. Umamaheswaran, V. S. Batra, and D. V. S. Bhagavanulu, "Development of biomass ash filters for high temperature applications," in Proceedings of the International Symposium of Research Students on Materials Science and Engineering, pp. 1-8, Decemeber 2004.

[20] G. Sua-Iam and N. Makul, "Use of increasing amounts of bagasse ash waste to produce self-compacting concrete by adding limestone powder waste," Journal of Cleaner Production, vol. 57, pp. 308-319, 2013.

[21] J. A. Sadeeq, J. Ochepo, A. B. Salahudeen, and S. T. Tijjani, "Effect of bagasse ash on lime stabilized lateritic soil," Jordan Journal of Civil Engineering, vol. 9, no. 2, pp. 203-213, 2015.

[22] K. J. Osinubi, T. S. Ijimdiya, and I. Nmadu, "Lime stabilization of black cotton soil using bagasse ash as admixture," Advanced Materials Research, vol. 62, pp. 3-10, 2009.

[23] A. K. Sabat, "Utilization of bagasse ash and lime sludge for construction of flexible pavements in expansive soil areas," Electronic Journal of Geotechnical Engineering, vol. 17, pp. 10371046, 2012.

[24] S. Liu and L. Li, "Influence of fineness on the cementitious properties of steel slag," Journal of Thermal Analysis and Calorimetry, vol. 117, no. 2, pp. 629-634, 2014.

[25] R. Naik, S. J. K. Annamalai, N. V. Nair, and N. R. Prasad, “Studies on mechanisation of planting of sugarcane bud chip settlings raised in protrays," Sugar Tech, vol. 15, no. 1, pp. 27-35, 2013.

[26] N. Partha and V. Sivasubramanian, "Recovery of chemicals from pressmud-a sugar industry waste," Indian Chemical Engineer, vol. 48, no. 3, pp. 160-163, 2006.

[27] R. L. Yadav and S. Solomon, "Potential of developing sugarcane by-product based industries in India," Sugar Tech, vol. 8, no. 2-3, pp. 104-111, 2006.
[28] A. T. Manikandan and M. Moganraj, "Consolidation and rebound characteristics of expansive soil by using lime and bagasse ash," International Journal of Research in Engineering and Technology, vol. 3, no. 4, pp. 403-411, 2014.

[29] F. N. Teixeira and E. S. Lora, "Experimental and analytical evaluation of $\mathrm{NO}_{X}$ emissions in bagasse boilers," Biomass and Bioenergy, vol. 26, no. 6, pp. 571-577, 2004.

[30] G. C. Cordeiro, R. D. Toledo Filho, and E. M. R. Fairbairn, "Effect of calcination temperature on the pozzolanic activity of sugar cane bagasse ash," Construction and Building Materials, vol. 23, no. 10, pp. 3301-3303, 2009.

[31] E. V. Morales, E. Villar-Cociña, M. Frías, S. F. Santos, and H. Savastano Jr., "Effects of calcining conditions on the microstructure of sugar cane waste ashes (SCWA): influence in the pozzolanic activation," Cement and Concrete Composites, vol. 31, no. 1, pp. 22-28, 2009.

[32] ASTM, ASTM C 618 Standard Specifications for Coal Fly Ash and Raw or Calcined Natural Pozzolan for Use as A Mineral Admixture in Concrete, ASTM, West Conshohocken, Penn, USA, 1999.

[33] A. R. Pourkhorshidi, M. Najimi, T. Parhizkar, F. Jafarpour, and B. Hillemeier, "Applicability of the standard specifications of ASTM C618 for evaluation of natural pozzolans," Cement and Concrete Composites, vol. 32, no. 10, pp. 794-800, 2010.

[34] P. Julphunthong, "Chemical stabilization of loess in Northeast Thailand using the mixture of calcined marble dust waste and sugarcane bagasse ash waste," Geotechnical Engineering Journal of the SEAGS \& AGSSEA, vol. 46, no. 1, pp. 103-108, 2016.

[35] A. Bahurudeen, K. Wani, M. A. Basit, and M. Santhanam, "Assesment of pozzolanic performance of sugarcane bagasse ash," Journal of Materials in Civil Engineering, vol. 28, no. 2, Article ID 4015095, 2015.

[36] R. Alavéz-Ramírez, P. Montes-García, J. Martínez-Reyes, D. C. Altamirano-Juárez, and Y. Gochi-Ponce, "The use of sugarcane bagasse ash and lime to improve the durability and mechanical properties of compacted soil blocks," Construction and Building Materials, vol. 34, pp. 296-305, 2012.

[37] M. V. Madurwar, S. A. Mandavgane, and R. V. Ralegaonkar, "Use of sugarcane bagasse ash as brick material," Current Science, vol. 107, no. 6, pp. 1044-1051, 2014.

[38] J. Torres Agredo, R. M. de Gutiérrez, C. E. Escandón Giraldo, and L. O. González Salcedo, "Characterization of sugar cane bagasse ash as supplementary material for Portland cement," Ingenieria e Investigacion, vol. 34, no. 1, pp. 5-10, 2014.

[39] M. A. S. Schettino and J. N. F. Holanda, "Characterization of sugarcane bagasse ash waste for its use in ceramic floor tile," Procedia Materials Science, vol. 8, pp. 190-196, 2015.

[40] J. M. Rodríguez-Díaz, J. O. P. García, L. R. B. Sánchez, M. G. C. da Silva, V. L. da Silva, and L. E. Arteaga-Pérez, "Comprehensive characterization of sugarcane Bagasse ash for its use as an adsorbent," Bioenergy Research, vol. 8, no. 4, pp. 1885-1895, 2015.

[41] J. F. Martirena Hernández, B. Middendorf, M. Gehrke, and H. Budelmannt, "Use of wastes of the sugar industry as pozzolana in lime-pozzolana binders: study of the reaction," Cement and Concrete Research, vol. 28, no. 11, pp. 1525-1536, 1998.

[42] D. Tonnayopas, "Green building bricks made with clays and sugar cane bagasse ash," in Proceedings of the 11th International Conference on Mining, Materials and Petroleum Engineering, pp. 7-14, Chiang Mai, Thailand, November 2013.

[43] V. Greepala and R. Parichartpreecha, "Effects of Using Flyash, Rice Husk Ash and Bagasse Ash as Replacement Materials on 
the Compressive Strength and Water Absorption of Lateritic Soil-Cement Interlocking Blocks," in in Proceedings of 9th Australasian Masonry Conference, pp. 583-603, 2011.

[44] P. Khobklang, K. Nokkaew, and V. Greepala, "Effect of bagasse ash on water absorption and compressive strength of lateritic soil interlocking block," in Excellence in Concrete Construction through Innovation: Proceedings of the Conference held at the Kingston University, United Kingdom, 9-10 September 2008, pp. 181-185, Taylor \& Francis, 2008.

[45] S. A. Lima, H. Varum, A. Sales, and V. F. Neto, "Analysis of the mechanical properties of compressed earth block masonry using the sugarcane bagasse ash," Construction and Building Materials, vol. 35, pp. 829-837, 2012.

[46] J. James, P. K. Pandian, K. Deepika, J. Manikanda Venkatesh, V. Manikandan, and P. Manikumaran, "Cement Stabilized soil blocks admixed with sugarcane bagasse ash," Journal of Engineering, vol. 2016, Article ID 7940239, 9 pages, 2016.

[47] J. James and P. K. Pandian, "Valorisation of sugarcane bagasse ash in the manufacture of lime-stabilized blocks," Slovak Journal of Civil Engineering, vol. 24, no. 2, pp. 7-15, 2016.

[48] A. P. Singh and P. Kumar, "Light weight cement-sand and bagasse ash bricks," International Journal of Innovative Research in Science, Engineering and Technology, vol. 1, no. 12, pp. 284287, 2015.

[49] A. Kulkarni, S. Raje, and M. Rajgor, "Bagasse ash as an effective replacement in flyash bricks," International Journal of Engineering Trends and Technology, vol. 4, no. 10, pp. 44844489, 2013.

[50] V. Priyadarshini, "Enhancement of mechanical properties of bagasse ash based hollow concrete blocks using silica fumes as admixtures," Civil and Environmental Research, vol. 7, no. 5, pp. 78-83, 2015.

[51] P. R. Rajkumar, K. D. Krishnan, P. T. Ravichandran, and T. A. Harini, "Study on the use of bagasse ash paver blocks in low volume traffic road pavement," Indian Journal of Science and Technology, vol. 9, no. 5, pp. 1-6, 2016.

[52] R. A. Naibaho, A. Rohanah, and S. Panggabean, "Utilization of bagasse ash to reduce the use of cement in brick making," Jurnal Rekayasa Pangan dan Pertanian, vol. 3, no. 4, pp. 537-541, 2015.

[53] N. Ali, N. A. Zainal, M. K. Burhanudin, A. Aziz, and A. Samad, "Physical and mechanical properties of compressed earth brick (CEB) containing sugarcane bagasse ash," in Proceedings of the 3rd International Conference on Civil and Environmental Engineering for Sustainability (IConCEES '15), vol. 47, pp. 1-7, Melaka, Malaysia, 2016.

[54] R. Onchiri, K. James, B. Sabuni, and C. Busieney, "Use of sugarcane bagasse ash as a partial replacement for cement in stabilization of self-interlocking earth blocks," International Journal of Civil Engineering and Technology, vol. 5, no. 10, pp. 124-130, 2014.

[55] K. Saranya, M. Santhoshkumar, S. Sathish, S. Gopinath, and P. Parimelashwaran, "Recycling of bagasse ash and rice husk ash in the production of bricks," International Journal of Emerging Technology in Computer Science and Electronics, vol. 21, no. 4, pp. 61-67, 2016.

[56] M. Prasanth, R. Thomas, S. S. Socrates, S. S. Kumar, and S. S. Manu, "Experimental investigation on the compressive strength of pressed composite earth brick," International Journal of Research in Engineering and Technology, vol. 4, no. 8, pp. 9598, 2015.

[57] R. W. Salim, J. M. Ndambuki, and D. A. Adedokun, "Improving the bearing strength of sandy loam soil compressed earth block bricks using Sugercane Bagasse Ash," Sustainability, vol. 6, no. 6, pp. 3686-3696, 2014.

[58] M. A. S. Schettino and J. N. F. Holanda, "Processing of porcelain stoneware tile using sugarcane bagasse ash waste," Processing and Application of Ceramics, vol. 9, no. 1, pp. 17-22, 2015.

[59] V. Hariharan, M. Shanmugam, K. Amutha, and G. Sivakumar, "Preparation and characterization of ceramic products using sugarcane bagasse ash waste," Research Journal of Recent Sciences, vol. 3, pp. 67-70, 2014.

[60] V. S. Aigbodion, S. B. Hassan, T. Ause, and G. B. Nyior, "Potential utilization of solid waste (bagasse ash)," Journal of Minerals \& Materials Characterization \& Engineering, vol. 9, no. 1, pp. 67-77, 2010.

[61] S. R. Teixeira, R. S. Magalhães, A. Arenales, A. E. Souza, M. Romero, and J. M. Rincón, "Valorization of sugarcane bagasse ash: producing glass-ceramic materials," Journal of Environmental Management, vol. 134, pp. 15-19, 2014.

[62] BIS, IS 1725: Specification for Soil Based Blocks Used in General Building Construction, BIS, New Delhi, India, 1982.

[63] K. Umamaheswaran and V. S. Batra, "Physico-chemical characterisation of Indian biomass ashes," Fuel, vol. 87, no. 6, pp. 628638, 2008.

[64] N. Amin, "Study of pozzolonic reactions in Bagasse ash cementitious system with and without quicklime as a chemical activator," Chiang Mai Journal of Science, vol. 42, no. 2, pp. 429435, 2015.

[65] K. J. Osinubi, V. Bafyau, and A. O. Eberemu, "Bagasse ash stabilization of lateritic soil," in Appropriate Technologies for Environmental Protection in the Developing World, E. K. Yanful, Ed., pp. 281-290, Springer Science, 2009.

[66] M. Frias, E. Villar, and H. Savastano, "Brazilian sugar cane bagasse ashes from the cogeneration industry as active pozzolans for cement manufacture," Cement and Concrete Composites, vol. 33, no. 4, pp. 490-496, 2011.

[67] K. Ganesan, K. Rajagopal, and K. Thangavel, "Evaluation of bagasse ash as supplementary cementitious material," Cement and Concrete Composites, vol. 29, no. 6, pp. 515-524, 2007. 

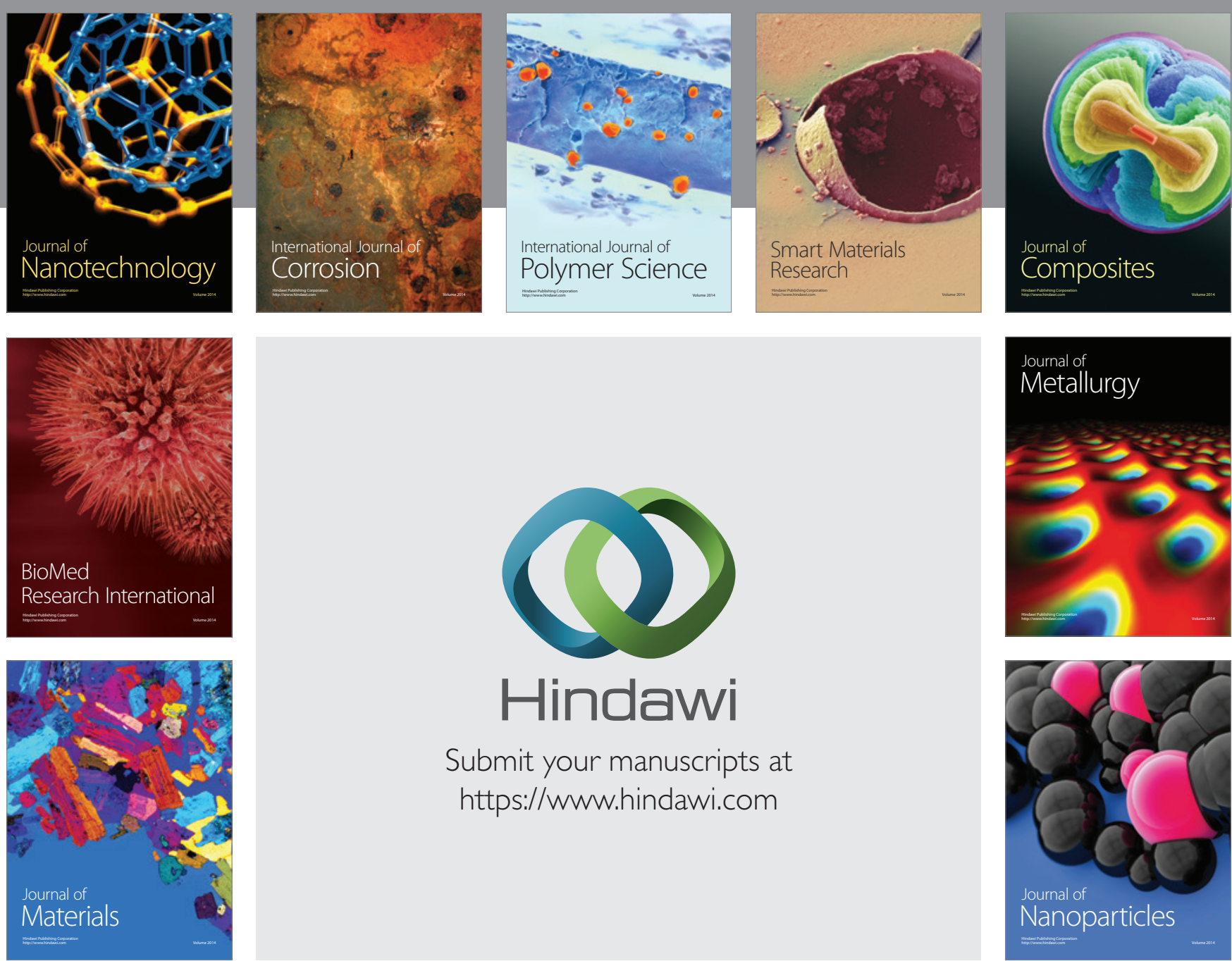

\section{Hindawi}

Submit your manuscripts at

https://www.hindawi.com

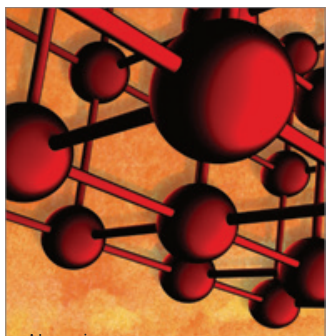

Materials Science and Engineering
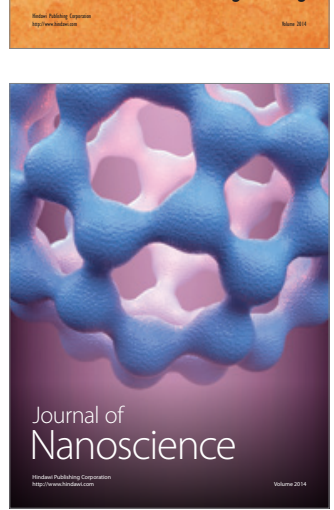
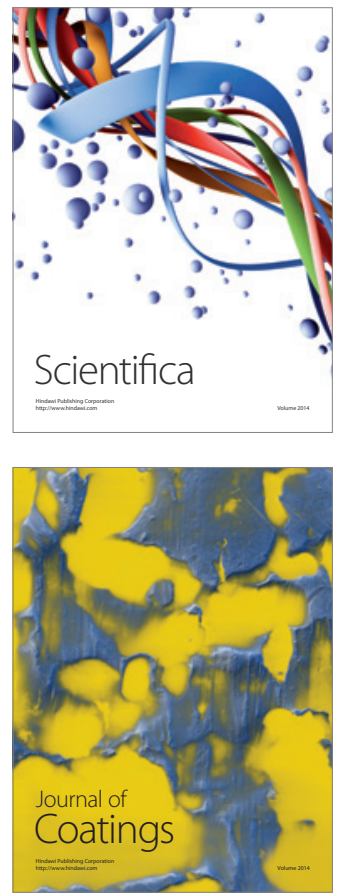
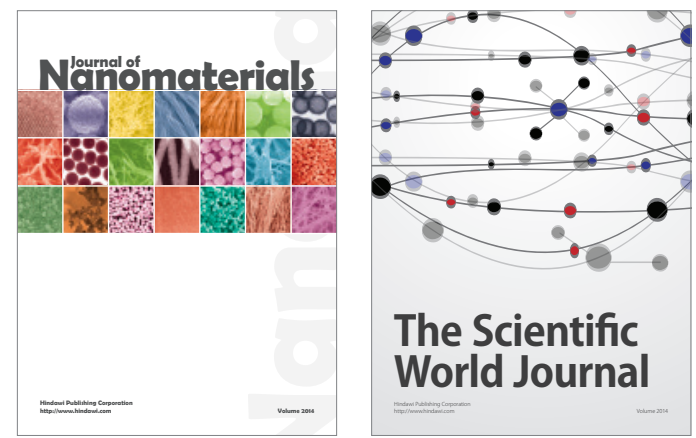

The Scientific World Journal
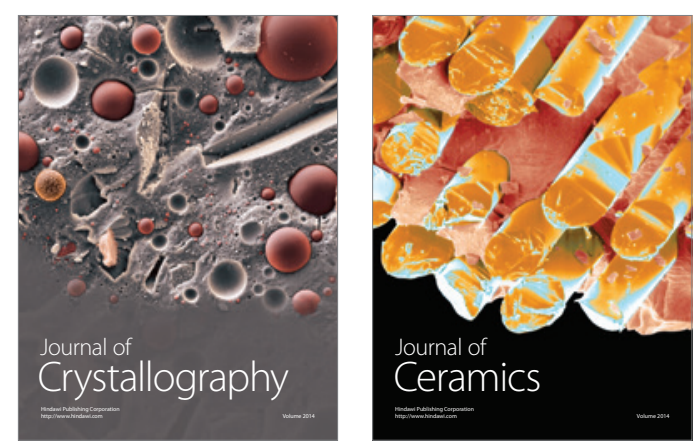
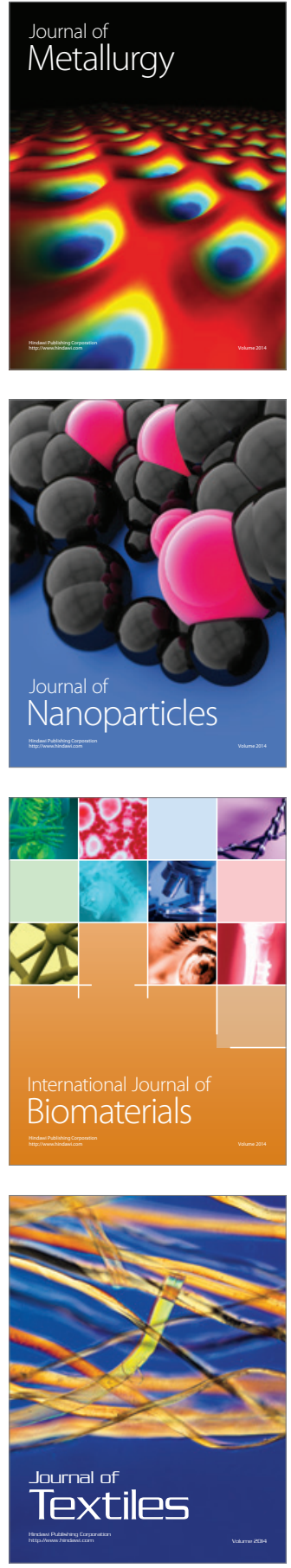